\title{
Comunicación para la concienciación social. Una mirada actualizada al documental social en el marco de las producciones digitales
}

\section{Communication for social awareness. An updated look at the social documentary in the framework of digital productions}

Alba Marín Carrillo*

Universidad Savoie Mont Blanc

Campus Jacob Bellecombette.

Rue Jean Baptiste Richard, 73000,

Jacob-Bellecombette, Francia

Editor: Rogelio del Prado Flores

Fecha de recepción: 29 de abril de 2020

Fecha de aceptación: 9 de mayo de 2020 alba-maria.marin-carrillo@univ-smb.fr https://orcid.org/0000-0003-0285-7086

https://doi.org/10.36105/stx.2020n5.02

\section{RESUMEN}

El objetivo principal de este trabajo es actualizar el estado de la cuestión del documental social y completar los estudios existentes incluyendo la producción documental en plataformas y medios digitales. Proponemos una breve revisión histórica para llegar a la producción contemporánea y comparar las tendencias y estrategias seguidas en esta práctica audiovisual. Hemos realizado un análisis visual a partir de un modelo propio con categorías tradicionales del análisis fílmico complementado con otras categorías específicas para los formatos digitales. El artículo muestra la continuidad de las tendencias tradicionales de la función social, comprometida y reivindicativa del documental, así como nuevas estrategias para la concienciación social.

Palabras clave: documental, cine, comunicación social, nuevas tecnologías, inmersión.

\section{ABSTRACT}

This paper responds to the need to update the state of the art of social documentaries and complete existing studios, including documentary production on digital platforms

\footnotetext{
* Doctora en Ciencias de la Información y de la Comunicación. Profesora del departamento de Comunicación Hipermedia de la Facultad de Letras, Lenguas y Ciencias Humanas de la Universidad Savoie Mont Blanc, Francia.
} 
and media. We propose a brief historical review to reach contemporary production and compare the trends and strategies followed in this audiovisual practice. We have applied a visual analysis based on our model with traditional categories of film analysis complemented with other specific categories for digital formats. The article shows the continuity of the usual trends of the social, committed and claiming function of the documentary, as well as new strategies for social awareness.

Keywords: documentary film; social communication; new technologies; immersion; interactive documentary.

\section{INTRODUCCIÓN}

$\mathrm{E}^{\mathrm{n}}$

n un contexto de cambio y experimentación, la vertiente más social y comprometida del documental encuentra nuevas estrategias o variantes de estrategias ya utilizadas para concienciar al espectador. Hablamos de prácticas que abarcan desde el documental activista que incorpora la creación de narraciones multiplataforma con diferentes grados de expansión hasta las producciones colaborativas en línea y los proyectos que pretenden impulsar acciones colectivas en la ciudadanía.

El documental ha sufrido una revolución en los últimos años a partir del desarrollo de los primeros formatos digitales interactivos. La realidad se representa de manera hipertextualy expandida. El webdocumental se impuso como el principal nuevo género, como el estandarte de la creación digital documental y los formatos inmersivos comienzan tímidamente a ganar terreno en la producción emergente. El video en 360 grados encabeza la lista de tecnologías inmersivas utilizadas para los relatos de no ficción y van apareciendo poco a poco historias de no ficción en realidad virtual que experimentan a nivel narrativo, juegan con la dimensión espacio-temporal e incorporan por primera vez conscientemente al cuerpo del espectador en su relación con el medio y la imagen.

La unión del arte con la realidad abre un lugar político en sí mismo, más allá de toda práctica representativa. El documental puede entenderse como forma de activismo político, especialmente aquellas producciones de corte social. Al igual que el arte público, abre su proceso creativo a la intervención del espectador, permitiéndole a este participar en los procesos de producción (Contreras, 20I8). Los productos de no ficción proponen experiencias visuales, pero también conforman espacios de visibilización, espacios colaborativos de creación y de convergencia.

El objetivo principal del artículo es completar y actualizar los estudios existentes sobre el panorama del documental social en los últimos diez años. Con ello pretendemos conti- 
nuar trazando la evolución de este subgénero, renovar el estado del arte y reflexionar sobre la incidencia de la informatización del documental en su función social y reivindicativa. Mostramos la vinculación entre la tradición de esta práctica y las expresiones digitales más contemporáneas para trazar una genealogía que llegue hasta las producciones emergentes.

En primer lugar, hemos trabajado un análisis de contenido fílmico a partir de un modelo propio desarrollado precedentemente (Marín, 2019). Incluye algunas de las categorías tradicionales del análisis fílmico: Barthes (2002, 2017); Belting (2007); Bordwell Casetti e di Chio (199I); Derrida y Stiegler (I998); Gaufreault y Jost (1995); Köster (2005); Nichols (20I0) o Plantinga (20I4), y otras propias del documental en formatos digitales como la inclusión del espectador o la expansión de la historia. A ello sumamos una amplia revisión bibliográfica y un trabajo de recopilación de obras. Partimos del análisis de documentales sociales en plataformas digitales para acceder al contenido desde la experimentación de los mismos. Posteriormente realizamos la puesta en relación de los resultados con el marco teórico existente como base del presente trabajo.

\section{CONCIENCIACIÓN Y MOVILIZACIÓN SOCIAL}

Lo que entendemos hoy en día como documental social comienza a realizarse a finales de la década de los años veinte, con una intención tanto revolucionaria como reformista. Entre los representantes de esta amplia corriente encontramos desde los exponentes del cine revolucionario ruso hasta los realizadores franceses del documental comprometido. Dziga Vertov, Joris Ivens, John Grierson o Jean Rouch son algunos de los nombres más representativos. La función social que asume el documental está muy presente desde las primeras prácticas y reflexiones sobre el género (Rotha, 1939). Ya con las primeras reflexiones sobre lo que puede ser el documental social se supera el mito de objetividad asociado en muchas ocasiones con consecuencias negativas a este género. Esta vertiente admite que su práctica no solo es un registro de la realidad, sino que es una interpretación personal, no exenta de polémica por la abierta manipulación que supone.

Paradójicamente, el documental social en sus inicios se encuentra al mismo tiempo unido al documental propagandístico y al periodismo cinematográfico. El ejemplo más claro de ello lo encontramos en el conocido realizador ruso Denis Akadievith Kaufman (Dziga Vertov), que comienza su carrera cinematográfica en el campo del periodismo cinematográfico en el primer periódico soviético sobre actualidad como redactor jefe del Kinonedelija (cine-Semana). Posteriormente dirige la revista filmada Goskino Kalendar entre I923 y 1925 y funda el noticiario Kino-Pravda. Este noticiario no tenía nada que ver con las anteriores 
actualidades que se realizaban, puesto que no se limitaban a la información, sino que dieron una interpretación artístico-periodística, siempre basada en la realidad soviética (Abramov, I965).

Pese a un montaje destacable, el objetivo principal de sus documentales era mostrar la realidad tal y como es, por lo que se llegaron a denominar "enemigos de la ficción". Ideológicamente, los kinoksse consideraban mostradores de la realidad con un fin más docente que lúdico. Para Vertov, el cine de ficción era su enemigo. Siempre decía, "hay que mostrar la vida tal cual es, la verdad de la vida” (Ara, 2008, p. I3) A ello hay que sumar su contradictoria visión sobre sus propias obras, que se encuadran en el documental propagandístico. Gauthier (2008) destaca la manera en la que se ha encasillado a Vertov en el documental propagandístico, olvidando parte de su trabajo tras la normalización del régimen bajo el mandato stalinista. "DzigaVertov, el brillante cineasta soviético que se opone al igualmente brillante Flaherty, es más un artista de vanguardia que practica alguna forma 'collages' basados en fragmentos de realidad que un propagandista (...) o un documentalista” (Gauthier, 2008, p. 53).

El director francés Jean Vigo es uno de los principales representantes del documental social en la vertiente reformista. Un director comprometido que explicaba del siguiente modo lo que para él significaba el documental social:

Este documental social se diferencia del documental sin más y de las actualidades semanales por el punto de vista defendido inequívocamente por el autor. Este documental social exige que se tome posición, porque pone los puntos sobre las íes. Si no implica a un artista, por lo menos implica a un hombre. Eso vale la pena. (Vigo, 2002, p. 35)

Esta declaración forma parte de la presentación que hizo el realizador de su conocido film A propos de Nice (1929). Vigo se posicionaba políticamente en contra del fascismo y unía su creación cinematográfica con su compromiso social. Su cine es un fiel reflejo de su visión crítica personal que evidencia la intolerancia y la injusticia (Vigo, 2002). De acuerdo con Lherminier (2007, p. 263) desde su película A propos de Niza, el realismo del documento es superado por el punto de vista del autor y todo lo que este agrega.

Si miramos hacia la Escuela Documental Británica con John Grierson, Paul Rotha y Robert J. Flaherty como los máximos representantes, tenemos un claro ejemplo del documental en su vertiente más educativa. Grierson también reclama el carácter artístico del documental, al que consideraba como un género superior, muy por encima de los noticiarios, a los que le atribuía una total carencia de estética (Grierson, I932-1934, cit. en Romagnuera y Alsina, I993, pp. I40-I4I). Rotha considera que el documental debe persuadir si quiere 
cumplir su función educativa y de concienciación. Es un documental que tiene un interés directo en la sociedad y en la toma de conciencia de los ciudadanos sobre los problemas sociales (Cebrián, I988).

Un paso más allá del reflejo de la cotidianidad o de la muestra de los problemas sociales se encuentran los documentales de tipo combativo, propagandístico y militante, claves también en la relación histórica entre el periodismo y el cine en el documental. El documental radical y de compromiso político que prolifera en EE.UU. en las décadas de los años treinta y cuarenta es un importante hito y una etapa clave en la historia del documental comprometido. La Workers Film and Photo League fue una organización de cineastas, fotógrafos y escritores que creían en el cine y la fotografía como instrumentos para el cambio social. La preocupación por ir más allá en el aspecto social de los documentales de denuncia llevó a estos realizadores a autoexigirse un mayor y mejor tratamiento de los temas, intensificando los recursos expresivos y buscando fórmulas de identificación con los personajes que consiguieran implicar de lleno al espectador. Únicamente con lograr la visibilidad de colectivos que generalmente no eran representados conseguía llegar a estos grupos para movilizarlos. The National Hunger March (Workers Film and Photo League, I93i) es un ejemplo de representación de colectivos de trabajadores y luchas sociales que busca la identificación y representación de los trabajadores.

La compañía cinematográfica independiente Frontier Films, fundada en EE.UU. en 1937 por Paul Strand, Leo Hurwitz y Joris Ivens se orientaba hacia dos frentes: la producción de documentales sobre problemas sociales estadounidenses, como el DustBowlo, el Crack del 29, y el tratamiento de conflictos internacionales con énfasis en la contención del fascismo en diferentes puntos geográficos. Según Gauthier (2008) y como el propio Paul Strand explica, estos documentalistas buscaban registrar la realidad, pero también tomar parte en ella. Según este autor, en referencia a las declaraciones de Strand sobre la necesidad de tomar partido de la realidad y no solo de representarla a través del cine o la fotografía: "Estas declaraciones, con más de treinta años de diferencia, dedicadas a dos artes de la imagen, enmarcan el período del humanismo roosveltiano y lo proclaman a su manera: la verdad de la imagen es revolucionaria” (Gauthier, 2008, p.7I).

El realizador holandés Joris Ivens destaca por el compromiso social de sus documentales con tintes experimentales. Algunos trabajos destacados y que coinciden con el tratamiento de conflictos internacionales son las películas sobre la guerra civil española filmadas entre 1937 y 1938:The Spanish Earth (Joris Ivens y John Ferno, 1937), Heart of Spain (Herbert Kline y Charles Korvin, 1937) y Return to Life (Henri Cartier-Bresson, 1938). El tratamiento fue más allá de la documentación o narración de los hechos, alcanzando fines propagandísticos y recurriendo a la teoría del montaje de Eisentein. Así, el montaje, la música o el ángulo adquirían la finalidad de convencer a los espectadores para llevarlos a la acción. 
De acuerdo con Aparicio (2013), el documental en las primeras décadas del siglo XX reclama un uso propagandístico del mismo, pero también acoge a documentalistas de lo social en la búsqueda de una estática propia. En la misma línea del documental social que se desarrolla en las primeras décadas del siglo XX, el cinéma vérité es heredero del cine etnográfico de Robert J. Flaherty, el cine-ojo de Vertov y el cine social de Jean Vigo. Uno de sus máximos representantes, Jean Rouch, consideraba a la cámara como un ente vivo que registra la realidad presentando la subjetividad del realizador.

\section{APARICIÓN DEL VIDEO Y USOS ALTERNATIVOS: EXPERIMENTACIÓN, CONTRAINFORMACIÓN Y SUBVERSIÓN A TRAVÉS DEL DOCUMENTAL}

En paralelo a la adaptación del documental a las dinámicas del medio televisivo, el video revoluciona el panorama audiovisual a partir de la década de los años sesenta empujando el desarrollo el documental de intervención social. El video va a propiciar una revolución en el panorama audiovisual en un contexto en el que confluyen movimientos contraculturales y artísticos comprometidos con la sociedad. Es en este contexto en el que la ligereza de los equipos lleva a la creación de estilos urbanos como los primeros films videográficos: las Street tapes o cintas de la calle. Estos videos fueron realizados por Les Levine, ayudante de Nam June Paik, y principalmente por Paul Ryan y Frank Gillette, cofundadores del grupo Raindance. El colectivo se posicionará de manera contestataria contra la industria mediática desde la producción de video de no ficción. Raindance Foundation se establece como organización crítica radical de medios y como promotora de una nueva era de democratización mediática. Uno de sus fundadores, Michael Shamberg publica su libro Guerrilla Televisión (197I), acuñando un concepto de guerrilla mediática como herramienta para romper las barreras impuestas por la televisión comercial. No se trataba ya de movilizar la acción social, sino de utilizar el video como herramienta política en sí misma. Esto supone un cambio de paradigma en la concepción del documental que se diferencia al mismo tiempo del documental propagandístico precedente.

Recordemos igualmente el conocido programa Challenge for change, calificado como documental activista en el libro publicado en 20 Io sobre este programa de la National Film Board of Canada (Société Nouvelle). Es en este contexto en el que se materializa el documental de intervención política, etiquetado como militante por el hecho de ser utilizado como herramienta de lucha e intervención.

Como indican Torreiro y Cartán (2005), utilizando como base las características del soporte del video se establece un estilo visual y se marcan las nuevas bases para la creación 
documental. El video no aparece hasta 1956 con el magnetoscopio de Ampex como soporte para conservar los programas de televisión y no será hasta mediados de los sesenta cuando comience a tener entidad con las primeras prácticas del videoarte (Checa, 2008). Su aparición, por la misma época que el Nuevo Periodismo, presentaba en su primera etapa el espíritu de finales de la década de los años sesenta. El nuevo medio era un territorio por explorar:

El nuevo territorio videográfico era, pues, una especie de terra incognita. El uso del nuevo soporte estaba cargado, por un lado, con el prestigio simbólico de los nuevos tiempos, y por otro, resultaba un territorio completamente virgen. Había que inventarlo todo en un nuevo medio que, para bien o para mal, se desarrollaba al margen de la adscripción de sus trabajos a algún tipo de tradición audiovisual previa. (Torreiro y Cartán, 2005, p. 169)

En su primera etapa, las creaciones abarcan desde lo que posteriormente se llamará videoarte hasta las nuevas prácticas documentales. Las bases documentales de las prácticas de aquel momento pasan por el videocomunitario y los trabajos realizados para la televisión. La aparición del video supone un nuevo punto de inflexión en la evolución del género documental. De nuevo, una variación en la historia del cine documental ligada a cambios en las herramientas técnicas.

La aparición del video hace que se replantee el concepto documental ya que, además de la experimentación de los nuevos videastas, una parte de los cineastas vieron las posibilidades estéticas que permitía. Estas posibilidades se traducen en nuevos modos de contar puesto que, siguiendo a Weinrichter (2010) un nuevo medio impone —o posibilita— un nuevo lenguaje:

Yo nunca vi al video como a un enemigo o como a un intruso. Cuando a mediados de los años 80 se me cerraron todas las puertas del cine, vi al video como a una especie de resurrección. Murió el cine, viva el video (...) El video me permitió trabajar en una especie de collage posmoderno permanente, en el cual podía mezclar todos los formatos, incorporar materiales de archivo de fuentes diversas, generar textos y hacer efectos especiales que en cine tendrían costos prohibitivos. (Ospina en Weinrichter, 2010, p. 219)

El dispositivo de grabación y reproducción mediante imagen electrónica posibilita la experimentación con la narratividad y cambia los modos de construcción de la representación de la realidad. Además de suponer cambios en la estética de la imagen, "supuso la adopción de nuevos conceptos alrededor de las nociones de tiempo y espacio, conformando nuevos paradigmas en las formas que había adoptado la Modernidad desde el nacimiento del cine" 
(Sucari, 2009, p. 68). El video posibilita la simultaneidad entre el suceso, su grabación y su visualización.

Los primeros videastas se sienten atraídos por las implicaciones culturales, políticas y sociales de su utilización. Manuel Palacio en su búsqueda del eslabón perdido del documental explica cómo en el primer periodo del video, que llega hasta principios de la década de los años setenta, no existe un nombre claro para este medio ni una línea estilística. "Sus creadores y público ignoran si las prácticas caminan hacia el llamado videoarte o hacia un uso social o documental del medio" (Palacio, 20I4, p. IOo).

Desde la contrainformación, los videastas se relacionan con el medio televisivo. El pionero español Antoni Muntadas explora en sus obras las relaciones con los medios y el mundo televisivo. Su trabajo Cadaqués Canal Local (1974) es el primer ejemplo del uso alternativo de la televisión realizado en España. Se crean obras a medio camino entre el videoarte, el documental y el cine como las prácticas del fond footage, de metraje encontrado y remezcla, tan actuales en el arte digital (Martín-Prada, 2015). De las características de estas creaciones videográficas nacidas de la experimentación con el medio podemos destacar una en relación a su repercusión en el documental contemporáneo: la interactividad.

La participación y la interactividad pasan a ser central en el video comunitario desde el proceso de grabación hasta su exhibición. "La creación de un espacio común (interactivo) que comparten el videasta y el espectador y que nos acerca a una nueva manera de concebir los procesos audiovisuales contemporáneos (Torreiro y Cartán, 2005, p. 175). Se introduce así un concepto nuevo para el documental y que será clave para entender las trayectorias del documental social digital contemporáneo donde la experiencia del usuario es la base de la narrativa.

\section{MEDIOS Y DIGITALIZACIÓN}

En este contexto, la formación de equipos con profesionales provenientes de diferentes disciplinas se convierte en una necesidad. "Desde los primeros días del hipertexto, artistas, tecnólogos creativos y más recientemente documentalistas y periodistas han estado explorando las potencialidades de la informatización para el contenido de no ficción" (Rose, 20I8, p.3). Y es a partir de la última década cuando realmente se desarrolla esta exploración en lo que respecta al documental. La transformación del documental en el contexto actual pasa por la vinculación de cuatro áreas según Nichols (200I): el contexto institucional, la comunidad profesional, la audiencia y el contenido. Dicho de otra manera, la relación entre los principales agentes: documentalista, sujetos de la representación, audiencia, medio y contenido. 
Al observar y analizar la producción de los últimos años (Marín, 2019) vemos nuevas perspectivas disciplinarias a medida que diseñadores, informáticos y artistas tecnológicos se incorporan a los equipos de producción de documentales digitales. De igual manera, el propio perfil del documentalista o periodista que trabaja con formatos digitales se adapta. El documental evoluciona de la mano de la tecnología aumentando ese carácter híbrido que le ha acompañado desde sus orígenes entre arte, periodismo y comunicación. Las narrativas de no ficción se expanden dentro y fuera de la red, pasando de la pantalla de la televisión al museo, al espacio digital, a las redes sociales e incluso de vuelta al espacio urbano como parte de las narrativas transmediáticas.

Las redes sociales son una potente herramienta de difusión que también se convierten en plataformas narrativas como parte de relatos expandidos, como nuevos soportes audiovisuales de difusión o como catalizadores de la participación del usuario. En la observación de estas nuevas formas documentales encontramos la utilización de diferentes soportes como parte de esas narrativas expandidas. Pero también encontramos la emergencia de nuevas narrativas que utilizan plataformas o medios diferentes a los utilizados hasta el momento o que ofrecen formas creativas de aprovechar sus posibilidades. Hablamos de documentales realizados exclusivamente para ser difundidos y consumidos en una red social determinada y dirigidos a un público muy específico. Es el caso del documental francés $F A Q$, creado para ser consumido exclusivamente en la red social Snapchat.

Del mismo modo, el espacio urbano no solo forma parte del documental de manera puntual, sino como plataforma narrativa y experiencial. Los llamados documentales móviles o documentarylocation-basedmedia (MIT Open DoucmentaryLab, 2015) ofrecen historias en movimiento a través de la utilización de sistemas de localización o medios como la realidad aumentada. En cualquier caso, el espacio y la ubicación física son la clave de documentales como Les Parcours Sonores 3 D.34 North II 8 West (Knowlton, Spellman y Hight, 2002) o el conocido Rider Spoke (Blast Theory, 2007).

El público tiene una relación cada vez más activa con el contenido audiovisual y desde hace años tiene la posibilidad de elegir a la carta infinidad de contenido entre diferentes plataformas audiovisuales especializadas. Pero en el contexto de este trabajo nos referimos a un nivel superior de integración del usuario que llega hasta la implicación directa y personal con el documental. Los productos audiovisuales creados en plataformas digitales incluyen al espectador a través de la interacción en línea y la creación de contenido propio. Producciones en las que se aprecia literalmente el rol central que adquiere el usuario son los documentales realizados en formatos inmersivos, video en 360 grados o realidad virtual.

La creación de documentales en formato inmersivo como el video en 360 grados o la realidad virtual tiene muy poca trayectoria, por lo que aún se encuentra en un periodo de 
creación emergente. En los últimos años ha emergido la creación de historias de no ficción en estos formatos, pero por el momento observamos dificultades en su categorización. Con todo ello, asociamos tres características principales a la producción de estas obras: creación emergente, distribución limitada y heterogeneidad.

\section{TENDENCIAS DEL DOCUMENTAL SOCIAL EN PLATAFORMAS DIGITALES}

El análisis del que hemos partido para esta investigación corresponde en gran medida a los elementos que utiliza Ortega (2004) en su cartografía histórica del documental social. Identifica cuatro tendencias en las que se ha movido la tradición de este subgénero desde sus orígenes; tendencias que se articulan con base en tres dimensiones: las formas de representación adoptadas (recursos cinematográficos y audiovisuales), la manera de interpelar al espectador y los pactos comunicativos que se establecen con él y la posición ética y política con respecto a la realidad representada. Si aplicamos estas tendencias al contexto del documental digital para actualizar el estado del arte, vemos cómo las producciones son una continuidad de las prácticas tradicionales. Continuidad en las tendencias, pero diferencias en las estrategias que responden en gran medida a los formatos y sus posibilidades narrativas y experienciales.

Las cuatro tendencias que identifica se resumen a continuación:

I. Producciones que documentan realidades sociales minoritarias, invisibilizadas y que tiene una labor de contrainformación. Aquí la imagen tendría un valor principalmente referencia y descriptivo.

2. Documental militante, propagandístico o de agitación con un discurso que busca impactar emocionalmente al espectador. "Conjunto de producciones donde la agitación de las conciencias en pos de la acción o la respuesta política y social despunta como estrategia comunicativa primordial" (Ortega, 2004, p. 49).

3. Documentales en los cuales la intención de su realización supera a la producción de la propia película. El documental se convierte en un elemento más de procesos de transformación social o acción política. Pueden tener lugar en comunidades y se asocia a las prácticas del documental en los que los sujetos de la participación forman parte de la práctica.

4. Esta cuarta tendencia hace referencia a un nivel "superior de reflexión a través de diversas estrategias” (Ortega, 2004, p. 49). Es una tendencia algo menos específi- 
ca que incluye la apertura de las temáticas tradicionales del documental social a la subjetividad del realizador, los discursos autobiográficos y las historias cotidianas o familiares.

La mayoría de los documentales en plataformas digitales, desde interactivos hasta inmersivos, podrían perfectamente incluirse como continuidades de estas tendencias. Efectivamente, estas producciones se caracterizan por otorgar al espectador un rol central tanto en el propio relato como en la experiencia corporal y sensorial que algunos documentales ofrecen. Y, en gran medida, esto podría suponer una ruptura con la tradición del documental social en cuanto a estrategias de concienciación social. Sin embargo, consideramos que todas estas producciones mantienen una fuerte unión con las prácticas precedentes, conformando nuevas versiones actualizadas que incorporan estrategias mediáticas propias de los medios y formatos utilizados. Por lo tanto, no estaríamos hablando de nuevas tendencias, sino de nuevas prácticas mediáticas del documental social que responden a todas ellas pero que trabajarían especialmente estrategias de inclusión de las audiencias.

Documentales en 360 grados podrían perfectamente continuar con la primera tendencia, aquella que pretende dar visibilidad y que tiene principalmente una labor de contrainformación. En esta vertiente podríamos incluir los documentales en 360 grados que muestran duras realidades lejanas. El primer documental en explotar este medio con un fuerte componente humanitario fue Clouds Over Sidra (Gabo Arora y Chris Milk, 2015), al que siguen otras producciones como On the Brink of Famine. Urgence au sud soudan (Marcello Hopkins, 2017) o The Discplaced (The New York Times, 2015). En este formato inmersivo el espectador se sitúa en el centro de la imagen envolvente y percibe la totalidad del relato desde un plano subjetivo.

A la imagen referencial le sumamos la característica de la tecnología video 36o, que fomenta la sensación de inmersión y presencia. Esa función referencial y descriptiva de la imagen adquiere fuerza al similar una representación espacial envolvente que evoca la sensación de presencia del espectador en el lugar y situación que se muestra. Los formatos inmersivos emergen como potenciales herramientas de empatía (Chris Milk, 2015). Aunque no consideremos del todo adecuado el término, sí es cierto que el formato inmersivo se caracteriza por incluir al espectador de manera que facilita su capacidad para ponerse en el lugar del otro, clave para conseguir el objetivo de concienciación social. Sin embargo, para cumplir este objetivo no basta únicamente con el medio, sino que el conjunto de elementos de composición y narración de la obra deben acompañar para aprovechar esta característica.

La segunda tendencia hacía referencia al documental de propaganda y de agitación. Definitivamente, los formatos emergentes del documental buscan el impacto emotivo y cog- 
nitivo en el espectador. Es una estrategia que se pretende seguir a partir de la mayor movilización sensorial posible del usuario, con su inmersión virtual o a través de su identificación personal con la problemática que abordan. Con esta intención, colectivos activistas utilizan el documental en formativo inmersivo como herramienta de concienciación, precisamente para mantener la atención del espectador en el discurso e impactar emocionalmente. Un ejemplo es el cortometraje 42 días (2016), producido en 360을 por Igualdad Animal.

Pero, sin duda, es la tercera tendencia en la que mayor producción podríamos incluir, teniendo en cuenta que no se dan en ningún caso de forma aislada. Observamos una especial continuidad en la utilización del documental como parte de un proceso de transformación social o acción sociopolítica, en el seno de pequeñas comunidades o incluso con visión internacional. En esta tendencia nosotros diferenciamos dos vertientes: los documentales abiertos a la participación o creados de forma colaborativa y aquellos creados como catalizadores de la participación para impulsar movimientos o acciones individuales con un mismo fin.

En la primera vertiente identificamos a documentales participativos creados en plataformas online como espacios abiertos de colaboración y que evidencian la evolución de la vertiente colaborativa o del documental participativo (Michiel y Zimmermann, 2013). Estos casos conforman en sí mismos espacios políticos de intercambio, visibilización o reivindicación. Algunos ejemplos referentes son los documentales Question Bridge (Hank Willis Thomas, Bayeté Ross Smith, Kamal Sinclair y Chris Johnson, 2008) o Proyecto Qui$p u$ (Maria Court y Rosemarie Lerner, 2013-actualidad).

Referentes del documental colaborativo como herramienta de acción social los encontramos en las producciones de video comunitario latinoamericano de la década de los años setenta (Zavalae y Leetoy, 2016). También en el cine político de la década de los años sesenta, que no pretendía representar al pueblo o mostrar realidades alternativas, sino hacer emerger al pueblo en él (Aguilar, 2015, p. I8I). Como continuidad de estas prácticas y salvando las distancias, los documentales digitales colaborativos o participativos crean una estructura a modo de plataforma sobre la cual desarrollar el relato que conforma en sí mismo un acto más que una representación. Bien es cierto que el pueblo o la comunidad no interviene en todos los tramos, pero sí conforma una parte fundamental del mismo. El proceso de cocreación que pone en colaboración a los profesionales creadores de imágenes y a los sujetos de la representación necesita de una estructura que facilite la participación, la discusión y la evolución del proyecto. Estas producciones nos obligan a repensar el rol del director, así como del equipo de producción y sus funciones con respecto a la creación del relato. ¿Quién construye el relato? El núcleo creativo (Roig Telo, Sánchez-Navarro, y Leibovitz, 20I2) compuesto tradicionalmente por el equipo profesional tiene una funciones muy distintas a 
las que cumple en las obras audiovisuales tradicionales, incluso en el cine colaborativo en el que ese núcleo puede estar conformado por profesionales y ciudadanos.

Un elemento clave para abordar el proceso de creación es el espacio compartido. Helen de Michel y Patricia Zimmermann (Michiel y Zimmermann, 2013) desarrollan el concepto Open Space Documentary para referirse a las múltiples voces que se ponen en diálogo para crear el relato y reflexionar sobre las producciones documentales colaborativas, interactivas y participativas. En el mismo hilo, podemos utilizar el concepto espacio documental compartido para referirnos quizás a la característica más resaltable de estas producciones. El documental se concibe como una obra abierta al público para su construcción.

La segunda vertiente se encamina a la obtención de respuestas específicas por parte de los usuarios en concordancia con la denuncia o la lucha social que se extrae del documental. En algunos casos, la intervención del espectador como principal estrategia de concienciación social tiene que ver con la personalización del discurso. El espectador, además de explorar el contenido audiovisual, responde personalmente a una serie de preguntas o cede parte de su información personal. De esta manera el relato se convierte en individual y personalizado, ofreciendo diferentes resultados en función de las respuestas de los espectadores. Más allá de la estrategia de inclusión del espectador seguida por el documental, el objetivo directo de estos documentales es conseguir que el espectador llegue hasta el final del relato y realice alguna de las acciones propuestas. El documental Do Not Track (Gaylor, 2015), en la etapa final del relato, dirige al espectador hacia iniciativas internacionales promovidas por diversos colectivos sobre change.org. La plataforma de Zero Impunity intenta crear un movimiento ciudadano con dos líneas de acción: la creación de actividades llamadas performances ciudadanas con intervenciones mediáticas en el espacio urbano y las peticiones en diferentes países sobre change.org para luchar contra la violencia sexual.

\section{A MODO DE CONCLUSIÓN}

El recorrido del documental social hasta nuestros días nos muestra la continuidad de las tendencias, pero también el cambio en las estrategias de concienciación. La aparición del video supuso un cambio en las prácticas del documental comprometido. Con el desarrollo de los formatos digitales tiene lugar otro cambio que afecta principalmente a la relación entre el documental y el espectador.

Las tres dimensiones con base en las cuales se articulan las tendencias a las que hemos hecho referencia anteriormente muestran esa discontinuidad. Los recursos formales utilizados empleados están directamente relacionados con el medio utilizado y sus carac- 
terísticas. Así, la forma de representación que se desprende de un documental inmersivo difiere radicalmente de aquella resultante del documental móvil que crea una experiencia de acuerdo a la localización del usuario. La naturaleza de la imagen, su función y los marcos espacio-temporales varían en función del medio utilizado, lo cual muestra una discontinuidad con respecto al documental televisivo, audiovisual lineal o cinematográfico. La manera de interpelar al espectador y la forma en la que se crean la ilusión de la realidad o el pacto de confianza es la otra dimensión que nos muestra la evolución.

Es precisamente en esta última dimensión en la que mejor se aprecia la evolución a nivel práctico en los documentales sociales en plataformas digitales y la incidencia de las posibilidades que ofrecen estos soportes. Más que nunca tiene lugar un diálogo entre el documental y el espectador, posible gracias a las diferentes formas en las que el usuario se relaciona con el documental. Aquel yo performativo que aparece las películas de Mikel Moore o en Los espigadores y la espigadora, Agnès Varda, 2000, desde el personaje encarnado por el realizador se traslada ahora al espectador. La intención del documentalista de ubicarse en los lugares de la historia, de aparecer en la imagen como un agente central del proceso de representación e interpretación, de participar en el terreno y cuestionar directamente a los sujetos de la representación desaparece. En los documentales en plataformas digitales el protagonismo es del espectador. De hecho, es más que un espectador. Si seguimos la terminología francesa hablaríamos de utilisateur o incluso de espect-acteur, que experimenta en primera persona la historia o forma parte de la misma. Es el espectador el que se traslada virtualmente al espacio de los acontecimientos, es el espectador quien compone la narración, quien elige el orden, quien aporta contenido o quien participa de una acción social colectiva.

\section{REFERENCIAS}

Abramov, N. (1965). Dziga Vertov. Premier Plan, (35), SERDOC: Lyon.

Aguilar, G. (2015). Más allá del pueblo. Imágenes, indicios y políticas del cine. México: Fondo de Cultura Económica.

Aparicio, D. (2013). Creatividad en el documental informativo de largometraje en España. Trascendencia de los hechos de actualidad (tesis doctoral). Universidad Complutense de Madrid, España.

Aston, J., Gaudenzi, S., y Rose, M. (2017). i-docs. The Evolving Practices of Interactive Documentary. New York: Columbia University Press.

Cebrián, M. (1988). Fundamento de la teoría y la técnica de la información audiovisual. Madrid: Alhambra.

Checa, G. (2008). Historia de la comunicación: de la crónica a la disciplina científica. La Coruña: Netbiblo. 
Contreras, F. (2018). El arte en la cibercultura: introducción a una estética comunicacional. Madrid: Minerva.

Gauthier, G. (2008). Le documentaire un autre cinéma. Paris: Armand Colin.

Irigaray, F., y Lovato, A. (20I4). Hacia una Comunicación Transmedia. Rosario:UNR Editoria. Recuperado de http://chasqui.ciespal.org/index.php/chasqui/article/view/2298/html_55

Lherminier, P. (2007). Jean Vigo. Un cinéma Singulier. París: RAMSAY.

Marín, A. (2019). La evolución del documental audiovisual. De los formatos interactivos a las experiencias inmersivas (tesis doctoral). Universidad de Sevilla, España.

Martín-Prada, J. (2015). Prácticas artísticas e Internet en la época de las redes sociales. Madrid: Akal.

Michiel, H. D. E., y Zimmermann, P. R. (2013). Documentary as an Open Space. En The Documentary Film Book, 366-375.

MIT Open Documentary Lab. (2015). Mapping the intersection of two cultures: interactive documentary and digital journalism. MIT, Mcarthur Foundation.

Nichols, B. (1997). La representación de la realidad. Barcelona: Paidós.

Nichols, B. (2010). Introduction to Documentary (2a. ed.). Indiana: Indiana University Press.

Ortega, M. (2004). "Rupturas y continuidades en el documental social”. Secuencias: Revista de bistoria del cine, (29), 47-6I.

Roig, A., Sánchez-Navarro, J.,y Leibovitz, T. (2OI2). “Esta película la hacemos entre todos! Crowdsourcing y crowdfunding como prácticas colaborativas en la producción audiovisual contemporánea”. Revista ICONO I4. Revista Científica de Comunicación y Tecnologías Emergentes, IO(3), 25-40. https://doi.org/10.7195/ri14.v10i1.113

Romanguera, J. y Alsina, H. (ed). (1993). Textos y manifiestos del cine. Madrid: Cátedra.

Rose, M. (2018). The immersive turn: hype and hope in the emergence of virtual reality as a nonfiction platform. Studies in Documentary Film, I2(2), I32-I49. https://doi.org/10.1080/175032 $\underline{80.2018 .1496055}$

Rotha, P. (1960). The Film Till Now. A Survey of World Cinema. New York: Twayne Publishers.

Sucari, J. (2009). El Documental expandido: pantalla y espacio, (Tesis doctoral). Universidad de Barcelona, España. Recuperado de http://diposit.ub.edu/dspace/handle/2445/4I523

Sucari, J. (20I7). El documental social participativo: el protagonista como sujeto de la historia. Obra digital, (12), 69-85.

TED. (2015). Chris Milk: De cómo la realidad virtual puede crear la máquina de empatía definitiva. [Video]. Recuperado de https://www.youtube.com/watch?v=iXHil1TPxvA

Torreiro, C., y Cerdán, J. (2005). Documental y vanguardia. Madrid: Cátedra.

Vigo, L. (2002). Fean Vigo: une vie engagée dans le cinéma. París: Etoile-Chaiers du Cinéma CNDP.

Weinrichter, A., y Ungar, C. (2010). Doc: el documentalismo en el siglo XXI. Donostia-San Sebastián: Festival Internacional de Cine de Donostia-San Sebastián. 